\title{
P2X4-Receptor-Mediated Synthesis and Release of Brain- Derived Neurotrophic Factor in Microglia Is Dependent on Calcium and p38-Mitogen-Activated Protein Kinase Activation
}

\author{
Tuan Trang, ${ }^{1,2,3}$ Simon Beggs, ${ }^{1,2,3}$ Xiang Wan, ${ }^{1,2,3}$ and Michael W. Salter ${ }^{1,2,3}$ \\ ${ }^{1}$ Program in Neurosciences \& Mental Health, Hospital for Sick Children, Toronto, Ontario, Canada M5G 1X8, 2Department of Physiology, University of \\ Toronto, Toronto, Ontario, Canada M5S 1A8, and ${ }^{3}$ University of Toronto Centre for the Study of Pain, Toronto, Ontario, Canada M5G 1X8
}

\begin{abstract}
Microglia in the dorsal horn of the spinal cord are increasingly recognized as being crucial in the pathogenesis of pain hypersensitivity after injury to a peripheral nerve. It is known that P2X4 purinoceptors (P2X4Rs) cause the release of brain-derived neurotrophic factor (BDNF) from microglia, which is necessary for maintaining pain hypersensitivity after nerve injury. However, there is a critical gap in understanding how activation of microglial P2X4Rs leads to the release of BDNF. Here, we show that stimulating P2X4Rs with ATP evokes a biphasic release of BDNF from microglia: an early phase occurs within $5 \mathrm{~min}$, whereas a late phase peaks $60 \mathrm{~min}$ after ATP stimulation. Concomitant with the late phase of release is an increased level of BDNF within the microglia. Both phases of BDNF release and the accumulation within the microglia are dependent on extracellular $\mathrm{Ca}^{2+}$. The late phase of BDNF release and accumulation, but not the early phase of release, are suppressed by inhibiting transcription and translation, indicating that activation of P2X4R causes an initial release of a pre-existing pool of BDNF followed by an increase in de novo synthesis of BDNF. The release of BDNF is abolished by inhibiting SNARE (soluble $N$-ethylmaleimide-sensitive factor attachment protein receptor)-mediated exocytosis. Furthermore, we find that the P2X4R-evoked release and synthesis of BDNF are dependent on activation of p38-mitogen-activated protein kinase (MAPK). Together, our findings provide a unifying mechanism for pain hypersensitivity after peripheral nerve injury through P2X4R-evoked increase in $\mathrm{Ca}^{2+}$ and activation of p38-MAPK leading to the synthesis and exocytotic release of BDNF from microglia.
\end{abstract}

\section{Introduction}

A growing body of evidence indicates that pain hypersensitivity, a hallmark symptom of neuropathic pain that typically develops as a result of injury to a peripheral nerve, is critically dependent on microglia-neuron signaling in the dorsal horn of the spinal cord (Tsuda et al., 2005; Scholz and Woolf, 2007). After peripheral nerve injury, expression of the P2X4-receptor (P2X4R) subtype of ionotropic purinoceptor increases in microglia, but not in neurons or astrocytes, in the spinal dorsal horn ipsilateral to the nerve injury; this increase parallels the increase in pain hypersensitivity (Tsuda et al., 2003, 2008; Ulmann et al., 2008). Pharmacological blockade of P2X4Rs acutely reverses established pain hypersensitivity after nerve injury, and development of pain hypersensitivity is attenuated by suppressing P2X4R expression by antisense RNA (Tsuda et al., 2003) and is prevented in P2X4R

Received Nov. 30, 2008; revised Jan. 16, 2009; accepted Jan. 26, 2009.

This work was supported by grants from the Canadian Institutes of Health Research (CIHR; Grant number MT11219) and the Neuroscience Canada Brain Repair Program to M.W.S. M.W.S. is an International Research Scholar of the Howard Hughes Medical Institute and holds a Canada Research Chair (Tier I) in Neuroplasticity and Pain. T.T. was supported by a CIHR Fellowship. We thank Ron Bouchard for technical input on the project and Janice Hicks for helpful comments on this manuscript and for assistance with the microglia cultures.

Correspondence should be addressed to Dr. Michael W. Salter, Program in Neurosciences \& Mental Health, Hospital for Sick Children, 555 University Avenue, Toronto, Ontario, Canada M5G 1X8. E-mail: mike.salter@utoronto.ca.

D01:10.1523/JNEUROSC1.5714-08.2009

Copyright $\odot 2009$ Society for Neuroscience $\quad 0270-6474 / 09 / 293518-11 \$ 15.00 / 0$ null-mutant mice (Ulmann et al., 2008). Thus, microglial P2X4Rs are necessary for the ongoing expression of pain hypersensitivity after peripheral nerve injury.

Microglia elicit pain hypersensitivity by signaling to neurons in the dorsal horn nociceptive processing network (Inoue, 2006; Scholz and Woolf, 2007). Brain-derived neurotrophic factor (BDNF) has been shown to be a key molecule mediating this microglia-neuron signaling (Coull et al., 2005): acting via its cognate receptor, tropomyosin-related kinase B (TrkB), BDNF released from microglia signals to neurons in spinal lamina I to cause a rise in intracellular $\left[\mathrm{Cl}^{-}\right]$, thereby suppressing $\mathrm{GABA}_{\mathrm{A}}{ }^{-}$ and glycine-mediated inhibition in these cells. The disinhibition unmasks innocuous inputs to lamina I neurons and facilitates their responses to noxious inputs (Keller et al., 2007). The resultant aberrant output in this normally nociceptive, ascending pathway may serve as a basis for symptoms of neuropathic pain. Consistent with a role of BDNF as a key mediator of neuropathic pain, $B D N F^{+/-}$mice display attenuated pain hypersensitivity after nerve injury compared with wild-type mice (Yajima et al., 2005). Moreover, in P2X4R null-mutant mice, BDNF accumulates in dorsal horn microglia after nerve injury, indicating that P2X4Rs are critical for the release of BDNF from microglia in vivo (Ulmann et al., 2008).

A key unresolved question is how does $\mathrm{P} 2 \mathrm{X} 4 \mathrm{R}$ stimulation 
cause the release of BDNF from microglia? To address this question, we studied and manipulated microglia in primary culture, as these microglia show P2X4R-evoked release of BDNF and, when administered spinally to naive animals, these cells cause robust pain hypersensitivity comparable with that after peripheral nerve injury (Tsuda et al., 2003; Nasu-Tada et al., 2006). We found that stimulating P2X4Rs caused release of BDNF from an existing pool and increases BDNF expression. Both release and expression of BDNF were $\mathrm{Ca}^{2+}$-dependent and mediated via activation of p38-mitogen-activated protein kinase (MAPK), a kinase implicated in pain hypersensitivity after peripheral nerve injury (Jin et al., 2003; Tsuda et al., 2004; Zhuang et al., 2007). We also demonstrated that the P2X4R-stimulated release of BDNF occurs through soluble $N$-ethylmaleimide-sensitive factor attachment protein (SNAP) receptor (SNARE)-dependent exocytosis. Our findings, therefore, provide a paradigm for understanding the essential mechanistic steps in microglia: stimulation of P2X4R leads to influx of $\mathrm{Ca}^{2+}$ and activation of p38-MAPK which mediates increased synthesis and SNARE-dependent release of BDNF.

\section{Materials and Methods}

Primary microglia cultures. Primary microglia cultures were prepared as described previously by Tsuda et al. (2003). In brief, primary culture was prepared using postnatal (P1-P3) Sprague Dawley rat cortex and maintained for 10-14 d in DMEM medium (Invitrogen) containing 10\% fetal bovine serum (Invitrogen) and penicillin-streptomycin (1:1000; Wisent) at $37^{\circ} \mathrm{C}$ with $5 \% \mathrm{CO}_{2}$ and $95 \% \mathrm{O}_{2}$. Microglia were separated from the mixed primary culture by gentle shaking and replated on $100 \mathrm{~mm}$ plastic dishes for $2 \mathrm{~h}$ allowing healthy microglia to adhere to the surface. This method produced primary microglia cultures of $>95 \%$ purity.

For experiments, microglia were harvested from each $100 \mathrm{~mm}$ dish using a cell scraper and collected in $100 \mu \mathrm{l}$ of PBS (Wisent). To avoid potential dish-to-dish variability in the proportion of viable cells, all microglia harvested for each experiment were initially pooled and then equally aliquoted into Eppendorf tubes before treatment. To minimize potential variability in BDNF measurements, each experiment was performed with PBS- and ATP-only groups and responses normalized to PBS control.

Application of ATP and other drugs. Microglia aliquoted in Eppendorf tubes were stimulated by adding ATP ( $50 \mu \mathrm{M}$; Sigma) directly into the PBS extracellular solution. The concentration of ATP $(50 \mu \mathrm{M})$ used for this study has been shown to preferentially activate P2X4R but not P2X7R (Tsuda et al., 2003). After ATP stimulation, cells were returned to the $37^{\circ} \mathrm{C}$ incubator for the duration of the experiment which ranged from $5 \mathrm{~min}$ to $5 \mathrm{~h}$. Control groups received PBS, whereas drug treatment groups were pretreated before ATP stimulation as described below. At the end of the experiment, cells were treated with a phosphatase inhibitor mixture (2\%; Sigma) and a broad spectrum protease inhibitor $(2 \%$; Sigma) and centrifuged at $3000 \mathrm{rpm}$ for $6 \mathrm{~min}$. The pellet (microglia) was resuspended in 3\% SDS containing 15\% glycerol and $75 \mathrm{~mm}$ Tris-base and protein levels analyzed using Western blotting. Recovery of BDNF released from microglia into the supernatant was achieved using Microcon YM-10 centrifugal filter device (Millipore Bioscience Research Reagents) according to the manufacturer's instructions and the retentate assayed using a BDNF-specific ELISA kit (see below).

All drugs were prepared as stock solutions in either PBS or DMSO. The stocks were divided into single-use aliquots and stored at $4^{\circ} \mathrm{C}$ or $-20^{\circ} \mathrm{C}$ as required. In all experiments, the control groups without drug received the vehicle, and for DMSO, this was at final concentration that matched that of the drug-containing solution. The maximum final DMSO concentration was $0.1 \%$, and administering this concentration of DMSO had no effect on the release or accumulation of BDNF compared with PBS alone (not illustrated).

To examine the role of P2X4R in the ATP-evoked release of BDNF, cells were treated beginning $15 \mathrm{~min}$ before ATP stimulation with $2^{\prime}, 3^{\prime}$ O-(2,4,6-trinitrophenyl)adenosine $5^{\prime}$-triphosphate (TNP-ATP) $(10 \mu \mathrm{M}$;
Sigma; $1000 \times$ stock solution in PBS), an antagonist of P2X1-4R, or pyridoxalphosphate-6-azophenyl-2', $4^{\prime}$-disulphonoic acid (PPADs) (10 $\mu \mathrm{M}$; Sigma; $1000 \times$ PBS), an antagonist of P2X1-3,5,7R but not P2X4R.

To investigate the requirement of $\mathrm{Ca}^{2+}$ in the ATP-evoked BDNF responses, microglia were stimulated with ATP in normal extracellular solution, which contained $\mathrm{Ca}^{2+}(2 \mathrm{mM})$ or in extracellular solution with no added $\mathrm{Ca}^{2+}$. We also examined the effects of the $\mathrm{Ca}^{2+}$ ionophore A23187 ( $2 \mu \mathrm{m}$; Sigma; 2500× DMSO) and the sarcoplasmic reticulum/ endoplasmic reticulum (ER) $\mathrm{Ca}^{2+}$-ATPase inhibitor thapsigargin $(2 \mu \mathrm{M}$; Sigma; $2500 \times$ DMSO) on the release from and expression of BDNF in microglia. TNP-ATP was included in the extracellular solution in experiments using A23187 to prevent possible secondary activation of P2X4Rs by release of ATP from the microglia.

To address whether the increase in BDNF release and protein expression are mediated through increased transcription, translation, or both, cells were pretreated with actinomycin-D ( $1 \mu \mathrm{M}$; Sigma; 10,000 $\times$ DMSO) or cycloheximide ( $1 \mu \mathrm{M}$; Sigma; $10,000 \times$ DMSO $) 30$ min before ATP stimulation. Control groups were given cycloheximide or actinomycin-D in the absence of ATP stimulation to examine effect of these agents on basal BDNF levels.

To examine whether the ATP-evoked release of BDNF from microglia is dependent on vesicular-mediated exocytosis involving NSF attachment protein receptor (SNARE) proteins, we used the fusion peptide TAT-NSF700 which is comprised of two domains: an 11 aa HIV transactivating regulatory protein (TAT) domain fused to a 22 aa NSF domain (Matsushita et al., 2005; Morrell et al., 2005). Cells were treated with TAT-NSF700 (5 $\mu \mathrm{M}) 60 \mathrm{~min}$ before ATP stimulation. The control group was treated with a fusion peptide possessing identical amino acid composition but with a scrambled sequence TAT-NSF700scr (5 $\mu \mathrm{M}) 60 \mathrm{~min}$ before ATP stimulation. TAT-NSF fusion peptides were obtained from Anaspec (1000 $\times$ PBS). The sequence of TAT-NSF700 fusion peptide was YGRKKRRQRRR-GGG-LLDYVPIGPRFSNLVLQALLVL and TATNSF700scr was YGRKKRRQRRR-GGG-IPPVYFSRLDLNLVVLLLAQL.

To investigate whether BDNF released from microglia after ATP stimulation contributes to the increase in BDNF expression within the microglia, cells were treated with the BDNF-sequestering fusion protein TrkB-Fc ( $5 \mu \mathrm{g} / \mathrm{ml}$; $20 \times$ PBS $)$ immediately before ATP stimulation. Control group received the fusion peptide IgG-Fc $(5 \mu \mathrm{g} / \mathrm{ml} ; 20 \times \mathrm{PBS})$. TrkB-Fc and IgG-Fc were obtained from R\&D Systems.

The involvement of $\mathrm{p} 38$-MAPK was investigated using $\mathrm{p} 38$-MAPK inhibitor, 4-(4-fluorophenyl)-2-(4-methylsulfinylphenyl)-5-(4-pyridyl) $1 \mathrm{H}$ imidazole (SB203580) $(10 \mu \mathrm{m}$; Sigma; $1000 \times$ DMSO) and negative control 4-ethyl-2(p-methoxyphenyl)-5-(4'-pyridyl)-IH-imidazole (SB202474) (10 $\mu \mathrm{M}$; Calbiochem; $1000 \times$ DMSO). Activity of extracellular signal-regulated protein kinase (ERK) was inhibited by 2-(2-amino-3-methoxyphenyl)- $4 \mathrm{H}$ 1-benzopyran-4-one (PD98059) (5 $\mu \mathrm{M}$; Sigma; 1000× DMSO). C-Jun $\mathrm{N}$-terminal kinase (JNK) was inhibited by anthra[1,9-cd]pyrazol-6 $(2 \mathrm{H})$ one (SP600125) (5 $\mu \mathrm{M}$; Calbiochem; 1000× DMSO). Control groups received SB203580, SB202474, PD98059, or SP600125 in the absence of ATP stimulation.

Suppression of $P 2 X 4 R$ expression with small interfering $R N A$. The primary microglia cultures, prepared as described above, were transfected with small interfering RNA (siRNA) against P2X4R (Qiagen) in transfection reagent (Hi-PerFect Transfection Reagent; Qiagen) in accordance with the manufacturer's instructions. Four P2X4R siRNA oligomers with sequence (1) 5'-UACUUAUAUUUCUUGUCCC-3', (2) 5' UUGCAGUCCCACUUGAUCU-3', (3) 5' -UGGAAAUGUAACUUUAGGC-3', and (4) 5'-UAACUUUAGGCGUCACUGG-3' were pooled and transfected over $72 \mathrm{~h}$. Control cells were transfected with nontargeting siRNA or transfection reagent alone. The sequence of the nontargeting siRNA was 5'-AATTCTCCGAACGTGTCACGT-3'; this sequence does not have homology to any known mammalian genes (Qiagen). Briefly, siRNA in combination with the transfection reagent were diluted in serum-free DMEM, mixed and added to the microglia culture. After $72 \mathrm{~h}$ transfection, microglia were harvested and stimulated with ATP (described above). P2X4R protein level was assessed by Western blot analysis of microglial cell lysates and the functional effects of a change in P2X4R expression on ATP-evoked intracellular $\mathrm{Ca}^{2+}$ transients assessed by using the fluorescent $\mathrm{Ca}^{2+}$ indicator dye fura- $2 \mathrm{AM}$ 
(details described below) (see supplemental Fig. 1, available at www. jneurosci.org as supplemental material).

Detection of BDNF release from cultured microglia by ELISA. Measurement of BDNF secreted from microglia into the supernatant was performed using a BDNF-specific ELISA kit (detection range, 7.8-500 pg/ $\mathrm{ml}$ ) as described previously by Coull et al. (2005). Briefly, BDNF standards $(7.82-500 \mathrm{pg} / \mathrm{ml})$ and $100 \mu \mathrm{l}$ of supernatant sample were run in triplicate and incubated overnight at $2^{\circ} \mathrm{C}$ with shaking as instructed by the manufacturer (Millipore Bioscience Research Reagents). Samples were then washed and incubated with biotinylated mouse anti-BDNF monoclonal antibody at room temperature for $3 \mathrm{~h}$. This was followed by $1 \mathrm{~h}$ incubation with streptavidin-HRP conjugate. After treatment with 3,3',5,5'-tetramethylbenzidine substrate, samples were read by a spectrophotometer plate reader (Molecular Devices) at $450 \mathrm{~nm}$. Samples were considered BDNF positive if their signal was higher than the background signal and within the range of the standard curve. Each assay was run in the presence of PBS and ATP-only internal control groups and measurements expressed a percentage change from the PBS control group.

To determine whether BDNF is cleared from the microglia supernatant, exogenous BDNF recombinant protein ( $25 \mathrm{pg}$; Abcam) was added to the Eppendorf tube which contained the following: (1) the extracellular solution together with the microglial cells or (2) the extracellular solution alone, from which the microglia had been removed. After a 15 -min incubation period at $37^{\circ} \mathrm{C}$, samples were treated with a phosphatase inhibitor mixture (2\%; Sigma) and a broad spectrum protease inhibitor (2\%; Sigma). The level of BDNF in the supernatant was measured using the BDNF ELISA.

Detection of BDNF protein in cultured microglia by Western blotting. After microglia isolation, total protein content was measured using a BCA (bicinchoninic acid assay) protein assay reagent kit (Pierce). A standard curve for total protein was generated for each experiment. Samples were heated at $95^{\circ} \mathrm{C}$ for $10 \mathrm{~min}$ in $2 \times$ sample buffer consisting of $4 \%$ SDS, $20 \%$ glycerol, $0.2 \%$ bromophenol blue, $100 \mathrm{~mm}$ Tris-Cl, and Bondbreaker TCEP [tris(2-carboxyethyl) phosphine] solution (Pierce). Samples were electrophoresed on a 12\% SDS polyacrylamide gel and transferred onto a $2 \mu \mathrm{m}$ nitrocellulose membrane. The membrane was blocked with 5\% milk dissolved in PBS-T and then incubated overnight with either rabbit anti-BDNF (1:1000; Santa Cruz), rabbit anti-P2X4 (1:1500; Alomone), mouse anti-phospho-p38 MAPK (1:1000; Cell Signaling Technology), mouse anti-p38 MAPK (1:1000; Cell Signaling Technology), or mouse anti- $\beta$-actin (1:4000; Santa Cruz). After washing in TBS-T, the membrane was incubated for $1 \mathrm{~h}$ with the appropriate HRP-conjugated secondary antibody followed by enhanced chemiluminescence detection. To test for antibody specificity of BDNF and P2X4R, antibodies were preabsorbed with control BDNF or P2X4R peptide. In addition, blots were processed in the absence of BDNF primary antibody. As control, the PBS and ATP group were run concurrently in each gel and quantification of BDNF band intensity expressed relative to PBS control. For densitometric quantification, immunoblots were digitized on a flatbed scanner and digital images quantified using Image J analysis software [National Institutes of Health (NIH)]. A standard curve dilution series was generated using rat brain microglia cell lysate proteins of known concentration and the linear range of detection determined for the antibody used. Only values falling within the linear range were incorporated into the final analysis. Western blot analysis comparing BDNF expression in primary cultured microglia, without ATP or other stimulation, and whole homogenate from healthy rat brain, indicates that BDNF in whole-brain homogenate, normalized to total protein, is $\sim 80 \%$ greater than that in microglial lysate.

Fluorescence measurement of intracellular $\mathrm{Ca}^{2+}$ in microglia. Primary microglia in culture were prepared as described above and transferred to standard poly-L-lysine-coated coverslips and allowed to adhere for $24 \mathrm{~h}$. Before recording, cells were incubated at room temperature for $30 \mathrm{~min}$ with the fluorescent $\mathrm{Ca}^{2+}$ indicator dye fura-2 AM (2.5 $\mu \mathrm{M}$; Invitrogen) in extracellular recording solution containing $140 \mathrm{~mm} \mathrm{NaCl}, 5.4 \mathrm{~mm} \mathrm{KCl}$, $1.3 \mathrm{~mm} \mathrm{CaCl}_{2}, 10 \mathrm{~mm}$ HEPES, and $33 \mathrm{~mm}$ glucose, $\mathrm{pH}$ 7.35, osmolarity 315-320 mOsm. After fluorophore loading, cells were thoroughly rinsed with extracellular solution lacking fura-2 AM and mounted on an inverted microscope (Diaphot-TMD; Nikon). All experiments were done at room temperature $\left(20-22^{\circ} \mathrm{C}\right)$. For ATP experiments, a $5 \mathrm{~s}$ application of ATP $(50 \mu \mathrm{M})$ from a micropipette was used to evoke $\mathrm{Ca}^{2+}$ responses from individual microglia. For A23187 and thapsigargin experiments, drugs were applied by bath in the extracellular recording solution. As described previously in detail (Salter and Hicks, 1995), excitation light was generated from a $75 \mathrm{~W}$ xenon arc lamp and passed alternatingly through 340 or $380 \mathrm{~nm}$ bandpass filters (Omega Optical). The emitted light was directed through a $510 \mathrm{~nm}$ bandpass filter and the light collected by a photomultiplier tube detector. Data were acquired by computer at a rate of $\sim 2.5 / \mathrm{s}$ and were stored on a hard disk. The fluorescence ratio of emitted light with $340 \mathrm{~nm}$ excitation to that emitted with $380 \mathrm{~nm}$ excitation was calculated after baseline subtraction. The change in fluorescence ratio over the initial fluorescence ratio $(\Delta F / F)$ was calculated offline. Hardware and software for $\mathrm{Ca}^{2+}$ measurement were from Photon Technology International.

Quantification and statistics. Western blots were analyzed using Image $\mathrm{J}$ analysis software (NIH) to quantify band intensity and the data normalized to PBS or vehicle control. For Western blots and BDNF ELISA, statistical significance between treatment groups was determined by a one-way ANOVA followed by a Student-Newman-Keuls post hoc test for multiple comparisons between groups (Prism 2; GraphPad Software). $n$ values reported in this manuscript represent independent experiments. All data were expressed as mean \pm SEM. $p<0.05$ was considered significant.

\section{Results}

It has been demonstrated that pain hypersensitivity, comparable with that produced after peripheral nerve injury, is evoked in naive animals by acute intrathecal administration of primary cultured microglia in which P2X4Rs have been stimulated by applying ATP (Tsuda et al., 2003) leading to the release of BDNF (Coull et al., 2005). Therefore, we used microglia prepared under identical primary culture conditions to investigate the intracellular mechanisms involved in the P2X4R-stimulated release of BDNF. We first characterized the time course of release by measuring the amount of BDNF in the microglial supernatant for periods up to $5 \mathrm{~h}$ after adding ATP $(50 \mu \mathrm{M})$ (Fig. 1). We found that the level of BDNF in the supernatant was significantly increased at $5 \mathrm{~min}$, and at 60 min after adding ATP, each compared with PBS control, indicating that ATP stimulation evoked two distinct phases of BDNF release (Fig. 1a). The decline in BDNF after each the 5 min and 60 min peaks was attributed to degradation in the extracellular space, as exogenously administered BDNF added to the supernatant with or without microglia declined $20 \pm 11(n=5)$ versus $28 \pm 14(n=5) \mathrm{pg} / \mathrm{ml}$, respectively, over $15 \mathrm{~min}(p>$ $0.05)$, sufficient to account for the removal of the amount of BDNF released endogenously during ATP stimulation. The level of BDNF within the microglia increased after adding ATP (Fig. $1 b)$. However, in contrast with that released into the supernatant, the level of BDNF in the cells showed only a single phase, peaking 60 min after ATP addition.

To determine whether the effects of adding ATP were mediated by stimulation of P2X4Rs, we tested purinoceptor antagonists, TNP-ATP and PPADS, as well as siRNA suppression of P2X4R expression (Fig. 2). TNP-ATP is known to block P2X1-4 subtypes of P2XR and reverses peripheral nerve injury-induced pain hypersensitivity (Tsuda et al., 2003; Coull et al., 2005), whereas PPADS blocks P2X1,2,3,5,7Rs, but not P2X4Rs, and does not affect pain hypersensitivity after peripheral nerve injury (Tsuda et al., 2003). We found that in the presence of TNP-ATP $(10 \mu \mathrm{M})$, ATP had no effect on the level of BDNF in the supernatant at either $5 \mathrm{~min}$ or $60 \mathrm{~min}$ time points (Fig. $2 a$ ). Moreover, TNP-ATP did not affect BDNF in the supernatant at these times in controls treated with PBS without added ATP. Thus, TNPATP prevented the release of BDNF evoked by ATP. TNP-ATP 

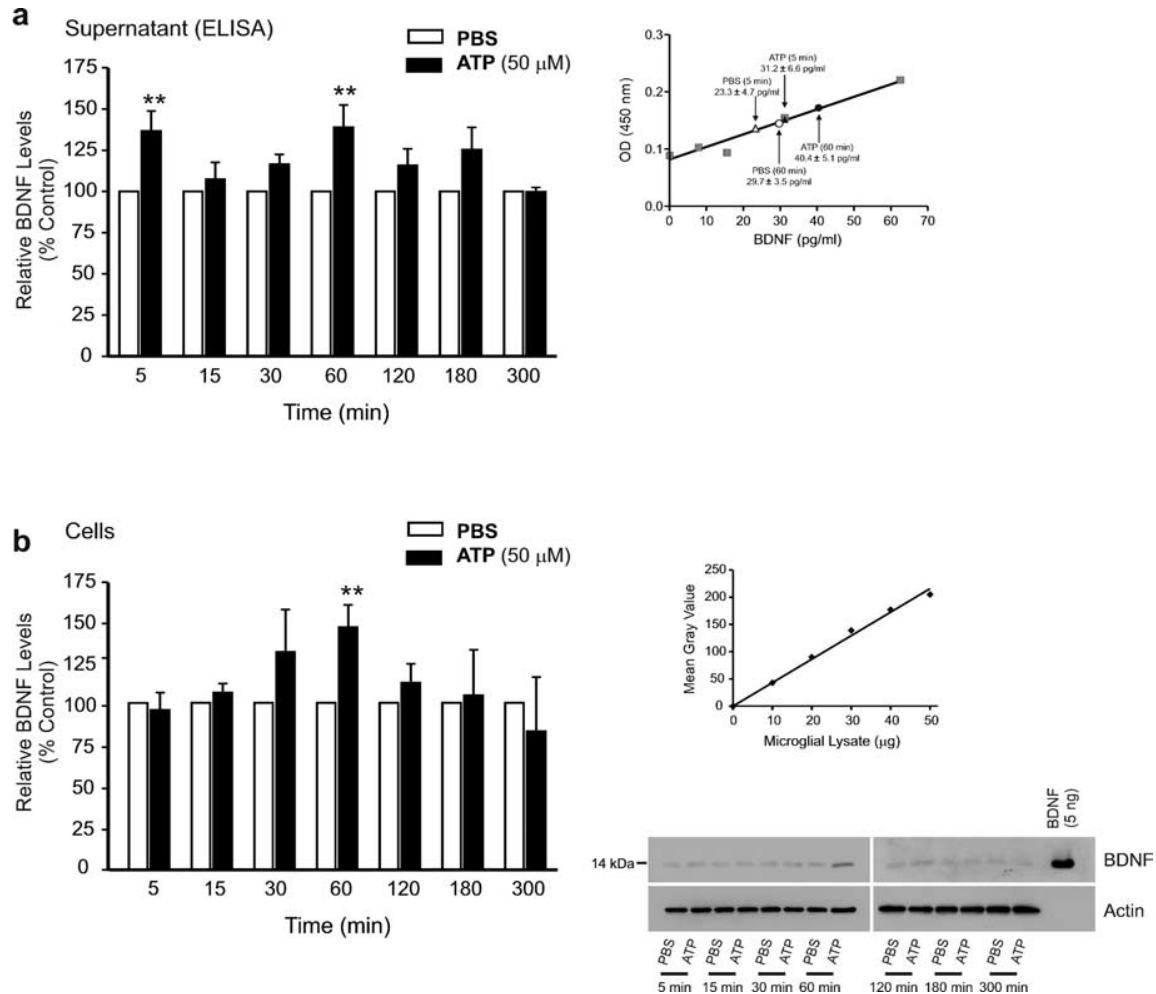

Figure 1. ATP causes a biphasic release of BDNF and an increase in BDNF protein in rat primary microglial culture. $\boldsymbol{a}$, Left, ELISA-based measurement of BDNF released into the supernatant at different time points after adding ATP. $\boldsymbol{a}$, Right, A representative BDNFELISA standard curve $\left(R^{2}=0.97\right)$; mean BDNF measurement for PBS and ATP $(50 \mu \mathrm{M})$ treated groups at 5 min and 60 min is indicated on the graph. $\boldsymbol{b}$, Left, Western blot analysis of BDNF protein in microglial cell lysates after adding ATP. Band intensity was quantitated as mean gray value and normalized to PBS-treated control. $\boldsymbol{b}$, Right, Representative standard curve derived from serial dilutions of primary microglial cell lysate proteins $\left(R^{2}=0.98\right)$. Representative Western blot of BDNF protein from microglial cell lysate. In each lane, $35 \mu \mathrm{g}$ of protein was loaded. Each time point represents $n=6-8$. Data are presented as mean percentage of PBS-treated control ( \pm SEM). ${ }^{* *} p<0.01$ compared with PBS-treated control.

also prevented the ATP-evoked increase in BDNF within the microglia (Fig. 2b) without affecting the control BDNF level. In contrast, PPADS $(10 \mu \mathrm{M})$ did not reduce ATP-evoked release or accumulation of BDNF (Fig. $2 a, b$ ), nor did PPADS affect control levels of BDNF in the supernatant or cells.

To determine the effects of suppressing P2X4R expression, we transfected the microglia with siRNA directed against P2X4R (5 $\mathrm{nM}$ ) or with scrambled control siRNA not targeting P2X4Rs (5 $\mathrm{nM})$. After transfecting (72 h), P2X4R protein level was $15.7 \pm$ $5.2 \%$ in the P2X4R siRNA-treated cells $(p<0.05 ; n=8)$ and $98.5 \pm 0.8 \%$ in the scrambled control siRNA $(n=6)$ cells compared with P2X4R protein level in vehicle-treated control. Moreover, in the P2X4R siRNA-treated cells, the transient $\mathrm{Ca}^{2+}$ response to applying ATP was decreased and maximum $\mathrm{Ca}^{2+}$ response $(\Delta \mathrm{F} / \mathrm{F})$ was $32.6 \pm 8.2 \%(n=10$ cells $)$ of the vehicletreated control cells; however, transient $\mathrm{Ca}^{2+}$ response to ATP in cells transfected with the scrambled control siRNA was comparable with vehicle-treated control (supplemental Fig. 1, available at www.jneurosci.org as supplemental material). The basal level of BDNF (i.e., without adding ATP) in microglia treated with P2X4R siRNA was not different from vehicle-treated control. Thus, treatment with P2X4R siRNA, but not with scrambled control siRNA, greatly reduced the expression of functional PX4Rs in the microglia but did not affect basal expression of BDNF. Under these conditions, we found that P2X4R siRNA blocked the ATPevoked release of BDNF into the supernatant (Fig. 2c) and the increase in BDNF in the cells (Fig. 2d). Conversely, neither release nor accumulation of BDNF was affected by the scrambled control siRNA. Together, our findings indicate that the release of BDNF from and its accumulation within microglia evoked by ATP stimulation are dependent on P2X4Rs. Furthermore, there appears to be no ongoing stimulation of P2X4Rs, i.e., without exogenously added ATP, driving the basal expression or release of BDNF.

Because P2X4Rs are nonspecific cation channels permeable to $\mathrm{Ca}^{2+}$ (Ralevic and Burnstock, 1998; North, 2002), we questioned whether the release or accumulation of BDNF may depend on an ATPstimulated increase in intracellular $\left[\mathrm{Ca}^{2+}\right]$ (Fig. 3). To test this, we stimulated the microglia with ATP in the normal extracellular solution, which contained $\mathrm{Ca}^{2+}$ (2 $\mathrm{mM}$ ) or in extracellular solution with no added $\mathrm{Ca}^{2+}$. The lack of added extracellular $\mathrm{Ca}^{2+}$ reduced the peak rise in intracellular $\left[\mathrm{Ca}^{2+}\right]$ in response to ATP by $>85 \%$ (supplemental Fig. 1, available at www. jneurosci.org as supplemental material). We found that both the early and the late phase of the ATP-evoked increase in BDNF in the supernatant were abolished in extracellular solution with no added $\mathrm{Ca}^{2+}$ (Fig. 3a). Likewise, the ATP-evoked increase in BDNF in the cells was blocked in $\mathrm{Ca}^{2+}$-free extracellular solution (Fig. $3 b)$. Thus, extracellular $\mathrm{Ca}^{2+}$ is required for the release and accumulation of BDNF caused by ATP. From these findings, we infer that influx of $\mathrm{Ca}^{2+}$ through $\mathrm{P} 2 \mathrm{X} 4 \mathrm{Rs}$ is a critical step linking stimulation of these receptors to the increase in BDNF expression in and release from microglia.

Given the requirement for extracellular $\mathrm{Ca}^{2+}$, we questioned whether influx of $\mathrm{Ca}^{2+}$ per se is sufficient to evoke the release and accumulation of BDNF in the microglia. To test this possibility, we used the $\mathrm{Ca}^{2+}$-ionophore A23187 $(2 \mu \mathrm{M})$ applied in the normal extracellular solution, which evoked a rapid and sustained increase in intracellular $\left[\mathrm{Ca}^{2+}\right]$ (supplemental Fig. $2 c$, available at www.jneurosci.org as supplemental material). TNP-ATP was included in the extracellular solution in experiments using A23187 to prevent possible secondary activation of P2X4Rs by release of ATP from the microglia. We found that A23187 increased the release of BDNF into the supernatant at $5 \mathrm{~min}$ and $60 \mathrm{~min}$ compared with PBS control (Fig. 3c). Furthermore, treatment with A23187 caused a concomitant increase in BDNF protein expression within the microglia at $60 \mathrm{~min}$ (Fig. $3 d$ ). In contrast, in extracellular solution with no added $\mathrm{Ca}^{2+}$, A23187 did not affect the BDNF level in the supernatant (Fig. $3 c$ ) or within the microglia (Fig. $3 d$ ). Together, the results indicate that influx of extracellular $\mathrm{Ca}^{2+}$ is sufficient to cause the release of BDNF and its accumulation within the microglia.

To determine whether release of $\mathrm{Ca}^{2+}$ from intracellular stores may cause BDNF release and accumulation, we used thapsigargin, an inhibitor of the ER $\mathrm{Ca}^{2+}$-ATPase that sequesters $\mathrm{Ca}^{2+}$ in ER stores. Treatment with thapsigargin $(2 \mu \mathrm{M})$ evoked a rapid rise and sustained increase in intracellular $\left[\mathrm{Ca}^{2+}\right]$ in the microglia (supplemental Fig. $2 b$, available at www.jneurosci.org 
a

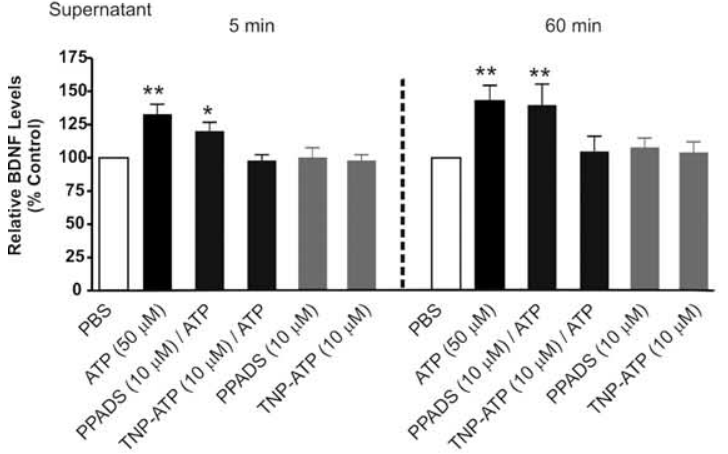

C

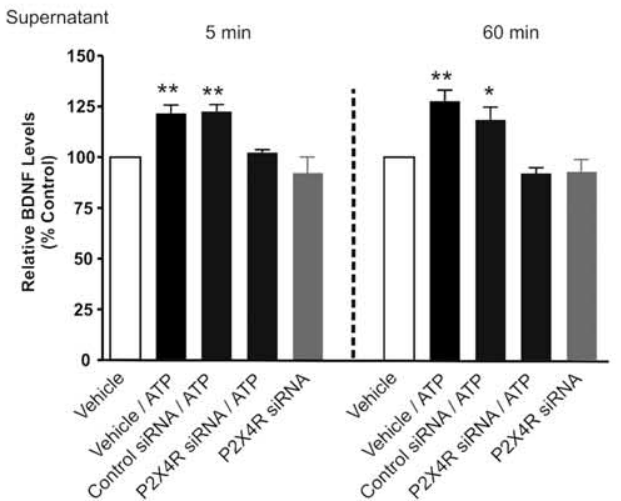

b

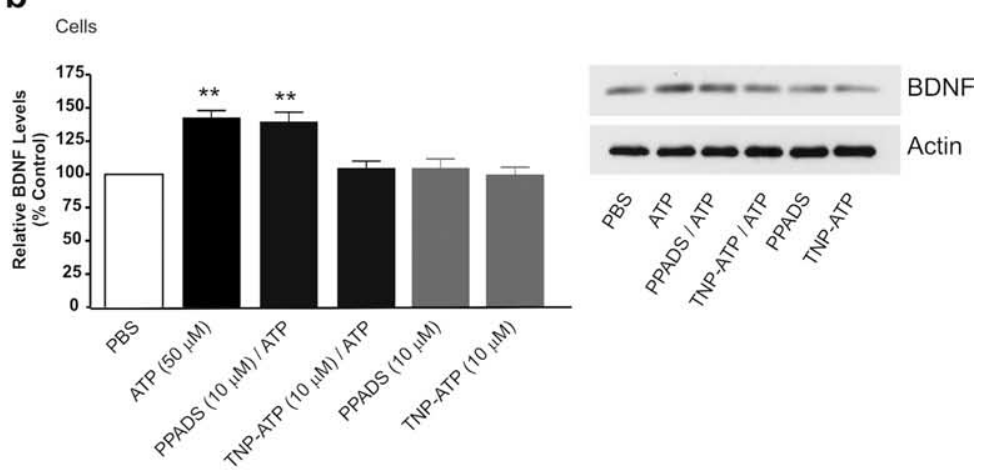

d

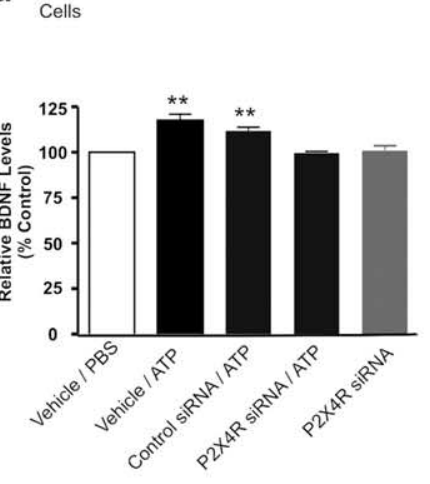

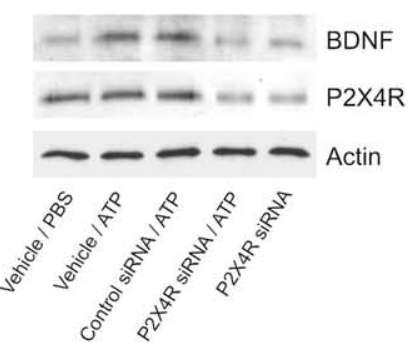

Figure 2. Blocking or suppressing expression of microglial P2X4Rs attenuates the ATP-evoked release and the accumulation of BDNF. $\boldsymbol{a}, \boldsymbol{b}$, Microglia were pretreated with pharmacological antagonists of P2XRs: TNP-ATP $(50 \mu \mathrm{m})$ or PPADs $(50 \mu \mathrm{m})$. $\boldsymbol{c}, \boldsymbol{d}$, Microglia were transfected with P2X4R-targeting siRNA (600 ng) over $72 \mathrm{~h}$; controls received vehicle-only or nontargeting siRNA (600 ng). $\boldsymbol{a}, \boldsymbol{c}$, Release of BDNF into the supernatant $5 \mathrm{~min}$ and $60 \mathrm{~min}$ after adding ATP $(50 \mu \mathrm{m})$ was measured by ELISA-based approach. $\boldsymbol{b}, \boldsymbol{d}$, BDNF protein expression 60 min after adding ATP was measured by Western blot analysis. The data are normalized to PBS control and expressed as percentage control ( \pm SEM). In siRNA transfection experiments, the data are normalized to vehicle control. Each experimental group represents $n=4-7$. ${ }^{*}$ Represents significant difference from PBS or vehicle control; ${ }^{*} p<0.05 ;{ }^{* *} p<0.01$.

as supplemental material). However, despite increasing intracellular $\left[\mathrm{Ca}^{2+}\right]$, thapsigargin had no effect on the release (Fig. $3 c$ ) or the expression of BDNF in the microglia (Fig. 3d). Similarly, neither BDNF release or accumulation were affected by treating the microglia with glutamate $(100 \mu \mathrm{M})$ (supplemental Fig. 3, available at www.jneurosci.org as supplemental material) or with lipopolysaccharide $(1 \mu \mathrm{g} / \mathrm{ml})$, both of which are known to cause release of $\mathrm{Ca}^{2+}$ from ER stores in microglia (Bader et al., 1994; D'Antoni et al., 2008). Thus, in contrast to influx of extracellular $\mathrm{Ca}^{2+}$, release of $\mathrm{Ca}^{2+}$ from ER stores was insufficient to cause the release of BDNF or its accumulation in the microglia.

We then addressed whether the BDNF released by stimulating $\mathrm{P} 2 \mathrm{X} 4 \mathrm{R}$ is from a pre-existing pool or is dependent on de novo synthesis of the protein. We treated the microglia with the transcriptional inhibitor, actinomycin-D $(1 \mu \mathrm{M})$, or with the translational inhibitor, cycloheximide $(1 \mu \mathrm{M})$. Neither of these inhibitors affected the level of BDNF in the supernatant when the microglia were treated with PBS without ATP (Fig. 4a). Moreover, the increase in BDNF in the supernatant 5 min after adding ATP was not affected by either actinomycin-D or cycloheximide. In contrast, each of these agents blocked the increase in the supernatant level of BDNF 60 min after adding ATP (Fig. 4a) and prevented the concomitant increase in BDNF protein in the cells (Fig. 4b). Because the early phase of BDNF release evoked by ATP was resistant to actinomycin-D and cycloheximide, this phase appears to be attributable to release per se of a pool of already synthesized BDNF. However, the late phase of P2X4R-stimulated
BDNF release and its accumulation in microglia are mediated by transcription and translation of BDNF.

We investigated whether the release of BDNF may be through exocytosis, as microglia are known to express SNAP-23 (Hepp et al., 1999), which is implicated in exocytosis in non-neuronal cells (Castle et al., 2002; Montana et al., 2006). Exocytosis mediated by SNAPs and SNAREs is dependent on the protein NSF, an ATPase which functions as a hexamer (Lowenstein and Tsuda, 2006). A 23 aa peptide of domain 2 of NSF (NSF700-722) interferes with NSF hexamerization, consequently inhibiting ATPase activity. Exocytosis in cells is known to be inhibited by a membrane permeant form, TAT-NSF700, comprised of NSF700-722 fused to the 11-amino protein transduction domain of the HIV Tat protein (TAT) (Morrell et al., 2005). A control peptide in which the order of NSF700-722 was scrambled (TAT-NSF700scr) is known to not inhibit SNARE-mediated exocytosis (Morrell et al., 2005). We found that administering TAT-NSF700 (5 $\mu \mathrm{M})$, starting $1 \mathrm{~h}$ before ATP stimulation, prevented the release of BDNF into the supernatant at $5 \mathrm{~min}$, whereas TAT-NSF700scr $(5 \mu \mathrm{M})$ had no effect (Fig. 5a). Neither TAT-NSF700 nor TATNSF700scr affected the level of BDNF in the supernatant of microglia that received only PBS (Fig. $5 a$ ) and neither affected the level of BDNF within the microglia after 5 min ATP stimulation (data not shown). Furthermore, the rise in intracellular $\left[\mathrm{Ca}^{2+}\right]$ evoked by ATP was not affected by either TAT-NSF700 or TATNSF700scr (supplemental Fig. 4, available at www.jneurosci.org as supplemental material). Thus, together, our findings indicate 

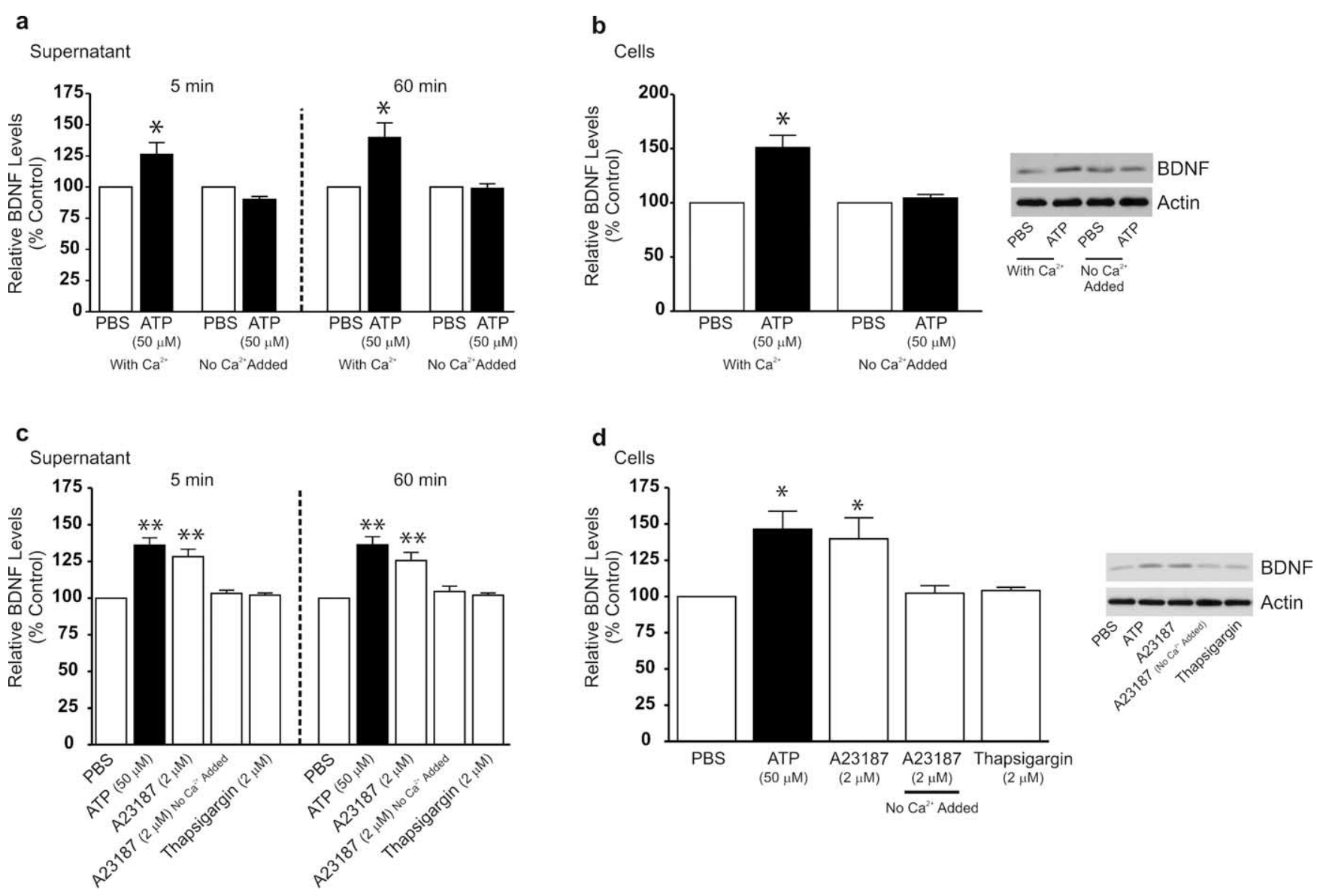

Figure 3. ATP-evoked release and accumulation of BDNF is dependent on the presence of extracellular $\mathrm{Ca}^{2+} \cdot \boldsymbol{a}, \boldsymbol{b}$, Microglia were stimulated with ATP (50 $\mu \mathrm{m}$ ) in extracellular solution containing $\mathrm{Ca}^{2+}(2 \mathrm{~mm})$ or in extracellular solution with no added $\mathrm{Ca}^{2+} \cdot \boldsymbol{c}, \boldsymbol{d}$, Microglia were treated with the $\mathrm{Ca}^{2+}$-ionophore A23187 (2 $\left.\mu \mathrm{m}\right)$ or with the sarcoplasmic reticulum/endoplasmic reticulum inhibitor thapsigargin $(2 \mu \mathrm{M}) . \boldsymbol{a}, \boldsymbol{c}$, ELISA-based measurements of BDNF release at $5 \mathrm{~min}$ and $60 \mathrm{~min}$ after drug treatment. $\boldsymbol{b}, \boldsymbol{d}$, Western blot analysis of BDNF protein in microglial cell lysates 60 min after drug treatment. TNP-ATP was included in the extracellular solution in experiments using A23187 to prevent possible secondary activation of P2X4Rs by release of ATP from the microglia. Data are normalized to PBS control and presented as mean percentage of PBS control ( \pm SEM). Each experimental group represents $n=5$. ${ }^{*} p<0.05 ;{ }^{* *} p<0.01$ compared with PBS-treated control.

that the release per se of pre-existing BDNF is by SNAREmediated exocytosis.

The ATP-stimulated release of BDNF at $60 \mathrm{~min}$ was also prevented by TAT-NSF700 but not by TAT-NSF700scr (Fig. 5a); neither of these affected the BDNF level in the supernatant with 60 min PBS treatment. Moreover, the accumulation of BDNF in the microglia with 60 min of ATP stimulation was significantly increased by TAT-NSF700, but TAT-SNF700scr had no effect on this accumulation (Fig. 5b). The level of BDNF within the cells treated only with PBS was not altered by treatment with TATNSF700 or TAT-NSF700scr. Collectively, these findings indicate that, like release of pre-existing BDNF, the release of newly synthesized BNDF stimulated by ATP is via SNARE-mediated exocytosis.

As microglia may express $\operatorname{TrkB}$, the cognate receptor for $\mathrm{BDNF}$, we questioned whether released BDNF contributes to the increase in BDNF expression within the microglia through a mechanism involving autocrine feedforward signaling (Canossa et al., 1997). Therefore, we examined the effect of the BDNFsequestering fusion protein TrkB-Fc (Mannion et al., 1999). We found in cells treated with TrkB-Fc $(5 \mu \mathrm{g} / \mathrm{ml})$, or with a control IgG-Fc $(5 \mu \mathrm{g} / \mathrm{ml})$, that the increase in BDNF expression evoked by ATP was not different than that evoked in microglia treated only with ATP (Fig. 5c). Furthermore, neither of TrkB-Fc nor IgG-Fc affected the basal level of BDNF in unstimulated micro- glia treated only with PBS. Together, these findings indicate that released BDNF does not signal back onto microglia to cause accumulation of BDNF within the cells during ATP stimulation.

We next investigated the intracellular-signaling pathway(s) through which stimulation of P2X4Rs leads to release and synthesis of BDNF. A candidate-signaling molecule implicated in pain hypersensitivity after peripheral nerve injury is the MAPK family member, p38-MAPK: peripheral nerve injury causes activation of $\mathrm{p} 38$-MAPK in microglia rather than in neurons or astrocytes in the dorsal horn, and pharmacological inhibition of this kinase both reverses and prevents the induction of pain hypersensitivity (Jin et al., 2003; Tsuda et al., 2004; Zhuang et al., 2007). Therefore, we wondered whether p38-MAPK is an intracellular mediator of the P2X4R-stimulated release or synthesis of BDNF in microglia. To this end, we tested the p38-MAPK inhibitor SB203580 and its inactive analog SB202474. We found that SB203580 $(10 \mu \mathrm{M})$ blocked the release of BDNF at $5 \mathrm{~min}$ and 60 min after ATP and, as well, prevented the increase in BDNF expression in the cells (Fig. 6). SB202474 (10 $\mu \mathrm{M})$ had no effect on either the release or accumulation of BDNF evoked by ATP. Moreover, neither SB203580 nor SB202474 affected the release or level of BDNF in control, PBS-treated, microglia. Thus, p38MAPK activity appears necessary for both the release and synthesis of BDNF evoked by P2X4R stimulation. In contrast, activity of the other two members of the MAPK family, MEK/ERK and JNK, 
appears not to be necessary because inhibitors of these kinases, PD98059 and SP600125, respectively, had no effect on the release or expression of BDNF (supplemental Fig. 5, available at www.jneurosci. org as supplemental material).

To investigate whether p38-MAPK is permissive or instructive in the signaling pathway from P2X4Rs to BDNF release and expression, we measured the level of phosphorylated p38-MAPK, the active form of this kinase (Chang and Karin, 2001). We found that adding ATP to the microglia increased the level of phosphop38-MAPK without changing the total expression of p38-MAPK protein (Fig. 7a). ATP induced a statistically significant increase in the phospho-p38 MAPK level at $60 \mathrm{~min}$ but not at $5 \mathrm{~min}$, and inhibiting p38 MAPK blocks the release of BDNF at both time points. Thus, it is possible that basal p38 MAPK activity may contribute to the early phase of the ATP-evoked release of BDNF. The increase in phosphop38-MAPK was prevented by TNP-ATP $(10 \mu \mathrm{M})$ but not by PPADS $(10 \mu \mathrm{M})$, indicating that the effect of ATP was mediated by P2X4Rs (Fig. 7b). Furthermore, the increase in phospho-p38-MAPK did not occur when ATP was applied in extracellular solution with no added $\mathrm{Ca}^{2+}$ (Fig. 7c). Moreover, treating with A23187 $(2 \mu \mathrm{M})$ mimicked the ATP-evoked increase in phospho-p38 MAPK (Fig. 7d), whereas thapsigargin $(2 \mu \mathrm{M})$ had no effect on the level of phospho-p38 MAPK (Fig. $7 d$ ). Collectively, we conclude that activation of p38-MAPK by $\mathrm{Ca}^{2+}$ influx through $\mathrm{P} 2 \mathrm{X} 4 \mathrm{Rs}$ mediates the increase in release and expression of BDNF.

\section{Discussion}

In the present study, we have identified key steps in the intracellular-signaling mechanism by which activation of microglial P2X4Rs leads to the release of BDNF. The most parsimonious explanation for our findings is that influx of $\mathrm{Ca}^{2+}$ through P2X4Rs causes activation of p38-MAPK that subsequently leads to increase in the SNARE-dependent release per se of BDNF and to an increase in BDNF synthesis (Fig. 8).

The blockade of the ATP-evoked release and accumulation of BDNF by TNP-ATP plus the resistance to PPADS is the pharmacological signature of responses mediated by P2X4Rs (Khakh et al., 2001; Tsuda et al., 2003). In addition, we found that inhibiting P2X4R expression with siRNA suppresses the effects of ATP on BDNF. Thus, our findings together provide strong evidence that the ATP-stimulated release and accumulation of BDNF requires activation of P2X4Rs. Microglia express several additional subtypes of purinoceptor that include P2X7R, P2Y1R, P2Y2R, P2Y6R, and P2Y12R (Färber and Kettenmann, 2006; Inoue, 2006). None of these other purinoceptors is affected by TNPATP and P2X7Rs, P2Y1Rs, P2Y2Rs, and P2Y6Rs are all blocked by PPADS at the concentration used in the present studies (Ralevic and Burnstock, 1998; Gallagher and Salter, 2003), indicating

a Supernatant

b Cells

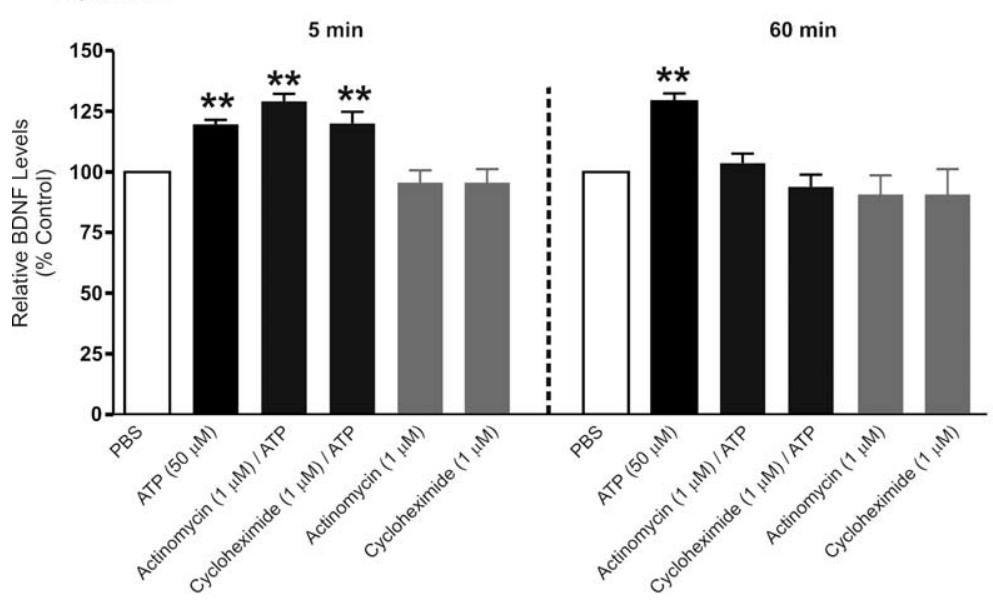

Figure 4. Inhibiting transcription or translation prevents the ATP-evoked late phase of BDNF release and the concomitant bot analysis of BDNF protein in microglial cell lysates $60 \mathrm{~min}$ after ATP stimulation. Data are presented as mean percentage of PBS-treated control ( \pm SEM). Each experimental group represents $n=5$. ${ }^{* *} p<0.01$ compared with PBS-treated control.

that none of these other purinoceptors is sufficient to mediate the BDNF release and accumulation evoked by ATP.

P2X4Rs are nonselective cation channels that are permeable to $\mathrm{Ca}^{2+}$ (North, 2002), and we demonstrated that extracellular $\mathrm{Ca}^{2+}$ is necessary for P2X4R-stimulated release of pre-existing and newly synthesized BDNF. Moreover, receptor-independent influx of $\mathrm{Ca}^{2+}$, but not release of $\mathrm{Ca}^{2+}$ from intracellular stores, was sufficient to cause release of BDNF. $\mathrm{Ca}^{2+}$ dependency is a hallmark of release by exocytosis, and we found that treatment with TAT-NSF700 abolished both the early and the late phase of P2X4R-stimulated BDNF release. Consistent with the blockade of release, the P2X4R-stimulated increase in BDNF expression was greater in microglia treated with TAT-NSF700 compared with cells not treated with TAT-NSF700. Based on these findings, we conclude that the P2X4R-stimulated release of BDNF from microglia involves a $\mathrm{Ca}^{2+}$ - and SNARE-dependent exocytotic pathway. SNARE-dependent exocytosis has not previously been established in microglia, but our conclusion is consistent with evidence that SNARE proteins SNAP-23, syntaxin-1, and cellubrevin are expressed in microglial cells (Hepp et al., 1999).

In contrast to the P2X4R-stimulated release of BDNF, the basal level of BDNF detected in the microglial supernatant is not dependent on (1) influx of extracellular $\mathrm{Ca}^{2+},(2)$ release of $\mathrm{Ca}^{2+}$ from intracellular stores, (3) P2X4Rs, (4) transcription, (5) trans- 
a

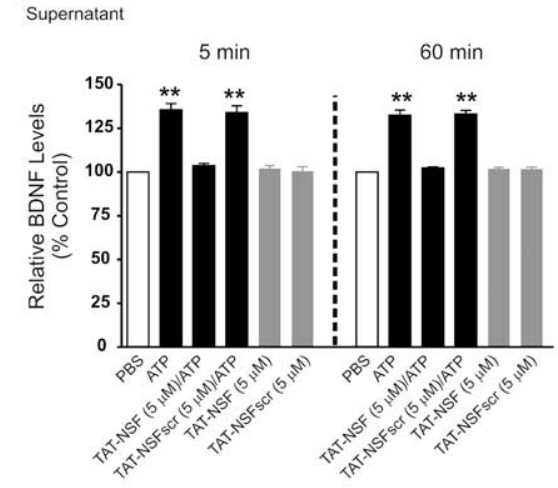

b
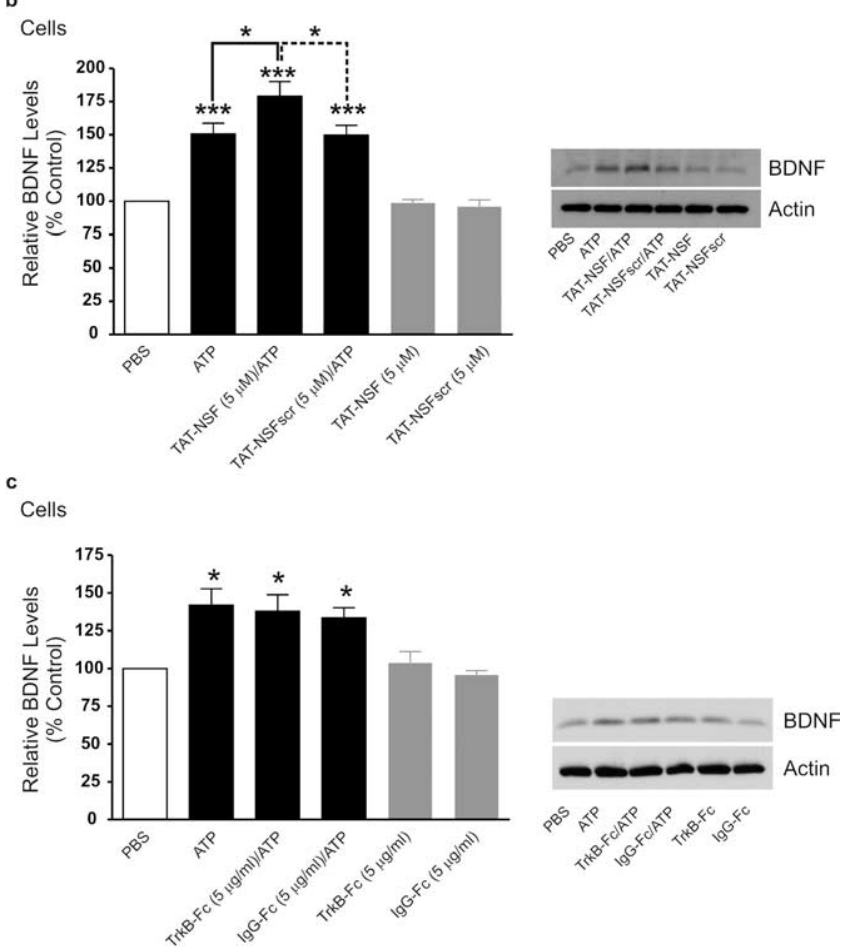

Figure 5. ATP-evoked release of BDNF from microglia is prevented by inhibiting SNAREmediated exocytosis, and BDNF-TrkB signaling is not required for accumulation of BDNF within the microglia. Microglia were treated with TAT-NSF700 (5 $\mu \mathrm{M})$, an inhibitor of SNAREmediated exocytosis, or control peptide TAT-NSF700scr $(5 \mu \mathrm{m}) 60$ min before ATP stimulation. $\boldsymbol{a}$, ELISA-based measurement of BDNF release $5 \mathrm{~min}$ and $60 \mathrm{~min}$ after ATP stimulation. $\boldsymbol{b}$ Western blot analysis of BDNF protein in microglial cell lysates 60 min after ATP stimulation. $\boldsymbol{c}$, Western blot analysis of BDNF protein in microglial cells lysates treated with the BDNFsequestering protein TrkB-Fc $(5 \mu \mathrm{g} / \mathrm{ml})$ or the control peptide lgG-Fc $(5 \mu \mathrm{g} / \mathrm{ml})$ at 60 min after ATP stimulation. Data normalized to PBS control and are presented as mean percentage of PBS control ( \pm SEM). TAT-NSF experiments represent $n=6$ for each experimental group. TrkB-Fc experiments represent $n=4$ for each experimental group. ${ }^{*} p<0.05 ;{ }^{* *} p<0.01$; ${ }^{* *} p<$ 0.001 compared with PBS-treated control.

lation, (6) p38 MAPK, ERK, or JNK signaling, or (7) SNAREdependent exocytosis. Thus, the basal level of BDNF appears not to be secretion but rather a background attributable to the methodology inherent to the harvesting of the microglial cultures. An important implication is that the basal level of $\mathrm{Ca}^{2+}$ - and SNARE-dependent exocytosis is negligible in comparison with the level of BDNF released by stimulating P2X4Rs.

$\mathrm{Ca}^{2+}$-dependent release of BDNF has been most well characterized in neurons where this neurotrophin is stored in large dense-core vesicles (Altar and DiStefano, 1998) and released from both presynaptic terminals and postsynaptic dendrites a
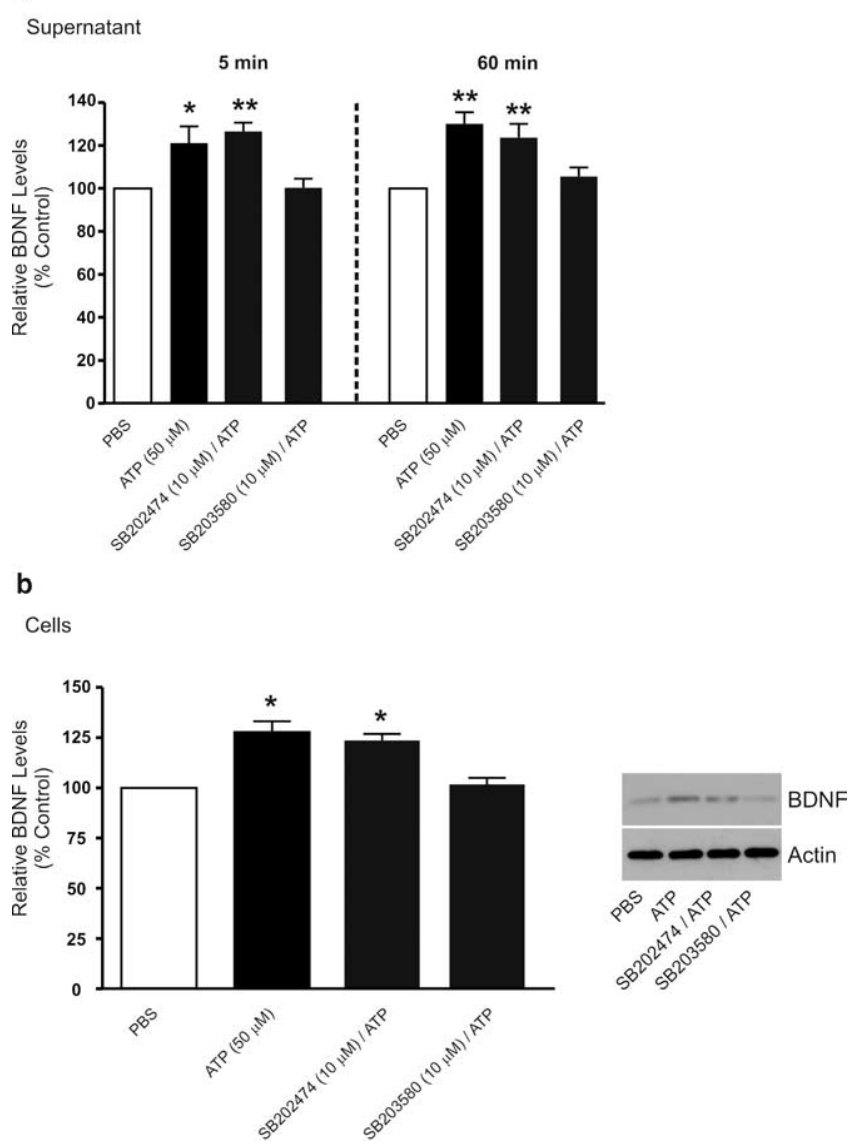

Figure 6. Treatment with the p38-MAPK SB203580 suppresses ATP-evoked BDNF release and synthesis. Microglia were treated with the p38-MAPK inhibitor SB203580 (10 $\mu \mathrm{M})$ or its inactive analog SB202474 $(10 \mu \mathrm{m}) \cdot \boldsymbol{a}$, ELISA-based measurement of BDNF release $5 \mathrm{~min}$ and 60 min after ATP $(50 \mu \mathrm{M})$ stimulation. $\boldsymbol{b}$, Western blot analysis of BDNF protein in microglial cell lysates $60 \mathrm{~min}$ after ATP stimulation. Data are presented as mean percentage of PBS-treated control ( \pm SEM). Each experimental group represents $n=5 .{ }^{*} p<0.05 ;{ }^{* *} p<0.01$ compared with PBS-treated control.

(Balkowiec and Katz, 2002; Kolarow et al., 2007). In nerve terminals, BDNF release triggered by depolarization depends on $\mathrm{Ca}^{2+}$ influx through voltage-gated $\mathrm{Ca}^{2+}$ channels and, as well, on release of $\mathrm{Ca}^{2+}$ from intracellular stores (Lever et al., 2001; Buldyrev et al., 2006). Release of BDNF from postsynaptic dendrites is also mediated by influx of $\mathrm{Ca}^{2+}$, initiated by opening NMDA receptors or voltage-gated $\mathrm{Ca}^{2+}$ channels (Kolarow et al., 2007). The role of intracellular $\mathrm{Ca}^{2+}$ stores in postsynaptic release of BDNF, however, depends on the type of stimulation as release triggered by high-potassium requires intracellular $\mathrm{Ca}^{2+}$ stores (Kolarow et al., 2007; Kuczewski et al., 2008) but that triggered by back-propagating action potentials or ongoing synaptic activity is not dependent on $\mathrm{Ca}^{2+}$ stores (Kuczewski et al., 2008). Presently, we found that stimulating release of intracellular $\mathrm{Ca}^{2+}$ with thapsigargin did not cause secretion of BDNF from microglia. Hence, microglial BDNF secretion may be independent of intracellular $\mathrm{Ca}^{2+}$ stores and, thus, similar to postsynaptic release of BDNF driven by back-propagating action potentials in neurons. The P2X4R-stimulated release of BDNF from microglia depends on activation of p38-MAPK. Involvement of protein kinases in release of BDNF is not without precedent as depolarization-evoked release of BDNF depends on CaMKII and protein kinase A in neurons (Kolarow et al., 2007; Kuczewski et al., 2008).

In addition to causing release of BDNF, P2X4R stimulation 

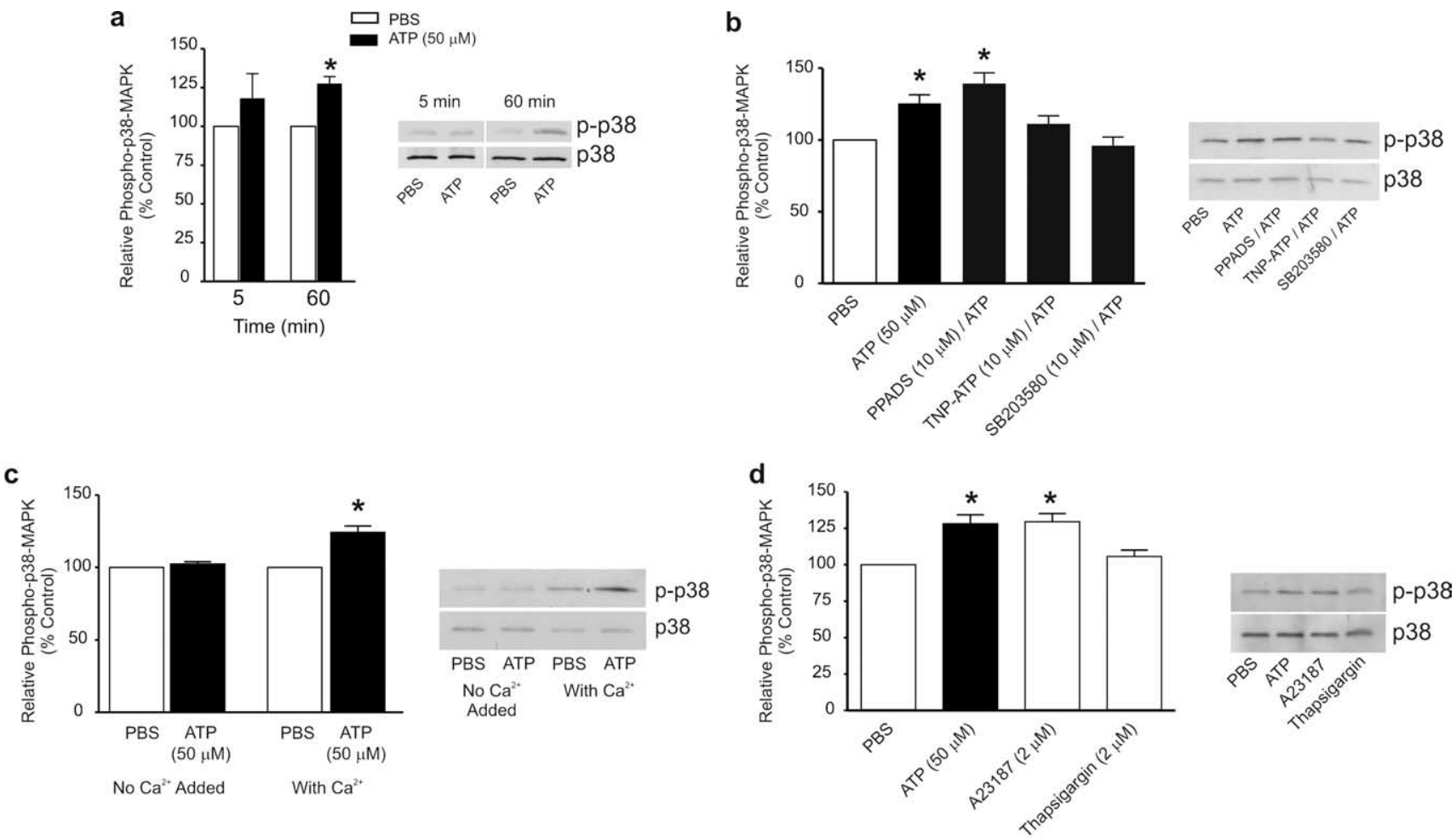

Figure 7. ATP-induced activation of p38-MAPK is prevented by TNP-ATP, SB203580, or in extracellular solution without $\mathrm{Ca}^{2+}$. $\boldsymbol{a}$, Western blot analysis of phospho-p38-MAPK expression in microglial cell lysates $5 \mathrm{~min}$ and $60 \mathrm{~min}$ after ATP $(50 \mu \mathrm{m})$ stimulation. $\boldsymbol{b}$, Effect of P2XR antagonists, PPADS (50 $\mu \mathrm{M}$ ) or TNP-ATP (50 $\mu \mathrm{M})$, and p38-MAPK inhibitor SB203580 (10 $\mu \mathrm{M})$, on phospho-p38-MAPK levels 60 min after ATP stimulation. c, Phospho-p38-MAPK expression in extracellular solution containing $\mathrm{Ca}^{2+}(2 \mathrm{~mm})$ or in extracellular solution with no added $\mathrm{Ca}^{2+} 60$ min after ATP stimulation. $d$, Effect of treatment with the $\mathrm{Ca}^{2+}$-ionophore $\mathrm{A} 23187(2 \mu \mathrm{M})$ or the sarcoplasmic reticulum/endoplasmic reticulum inhibitor thapsigargin $(2 \mu \mathrm{M})$ on phospho-p38-MAPK expression at 60 min after treatment. The data are normalized to PBS control and expressed as percentage control ( \pm SEM). Each experimental group represents $n=5 .{ }^{*} p<0.01$ compared with PBS-treated control.

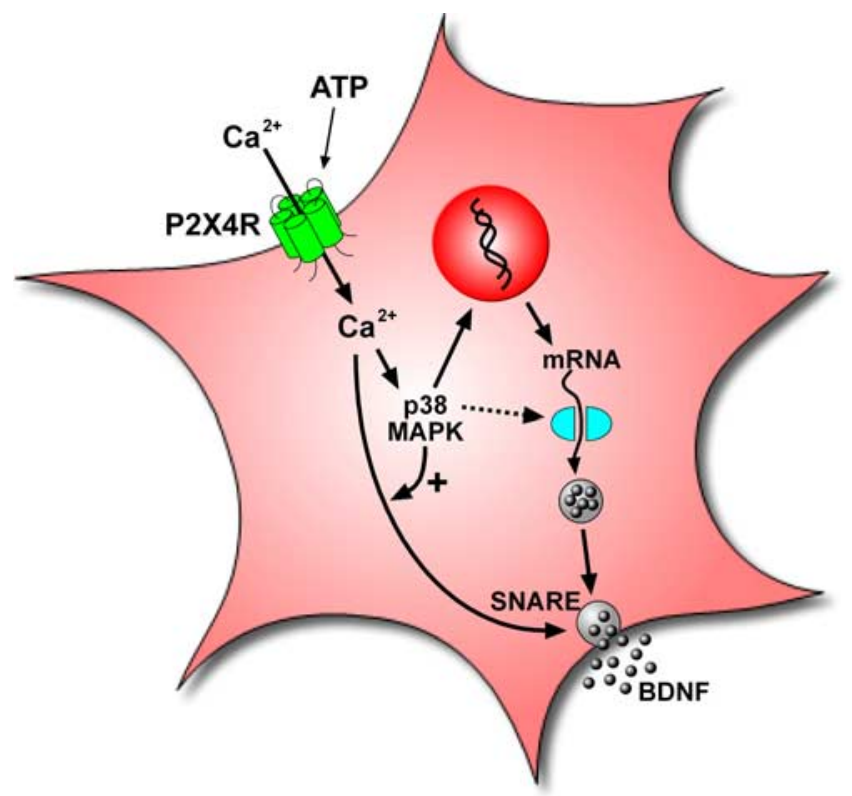

Figure 8. Model illustrating ATP-evoked BDNF release and synthesis from microglia. Stimulation of P2X4Rs by ATP causes the SNARE-mediated release and synthesis of BDNF that is dependent on extracellular $\mathrm{Ca}^{2+}$ and activation of $\mathrm{p38-MAPK}$. The early phase of release is from a pool of pre-existing BDNF, whereas the late phase of BDNF release and the accumulation of BDNF in the microglia are dependent on transcription and translation of de novo BDNF.

increased the BDNF level in the microglia. P2X4R stimulation increased both BDNF accumulation and release indicating that the accumulation was the result of de novo synthesis of BDNF rather than of a decrease in basal release of the peptide. The requirement for de novo synthesis was confirmed by treating with the transcription inhibitor actinomycin-D or the translation inhibitor cycloheximide, each of which prevented the accumulation of BDNF in the microglia. The effect of actinomycin-D indicates that stimulation of transcription by activating P2X4Rs is needed. Consistent with this, we have evidence that ATP administration increases BDNF mRNA in cultured microglia (T. Trang, M. Marchese, M. Fahnestock, and M. W. Salter, unpublished observations).

BDNF was originally identified in neurons as an immediateearly gene (Lauterborn et al., 1996; West et al., 2001), transcription of which is initiated by $\mathrm{Ca}^{2+}$ influx through L-type voltagegated $\mathrm{Ca}^{2+}$ channels or via NMDA receptors (Ghosh et al., 1994; Tao et al., 1998; Kolarow et al., 2007). Our findings, therefore, demonstrate that $\mathrm{Ca}^{2+}$-dependent stimulation of BDNF transcription is common to neurons and microglia. In neurons, stimulus-evoked increase in $\mathrm{Ca}^{2+}$ has been shown to activate key transcription factors implicated in the upregulation of BDNF gene expression including cAMP response element binding protein (Tao et al., 1998) and nuclear factor kappaB (Lipsky et al., 2001; Marini et al., 2004). A rise in intracellular $\left[\mathrm{Ca}^{2+}\right]$ is also reported to increase BDNF transcription by disinhibiting methyl-CpG-binding protein 2, a protein that represses expression of the BDNF gene (Chen et al., 2003; Zhou et al., 2006). Whether the P2X4R-stimulated increase in BDNF transcription in microglia found presently involves these transcription factors, or others, is as yet undetermined.

Neuronal expression of BDNF is upregulated by ERK and p38-MAPK-signaling pathways (Ji and Woolf, 2001; Obata et al., 2004; Rao et al., 2007). Activation of these pathways in spinal microglia has been shown to contribute to the development of neuropathic pain behaviors in nerve-injured rats (Jin et al., 2003; 
Tsuda et al., 2004). Presently, we found that the ERK inhibitor PD98059 has no effect on the release or the accumulation of $\mathrm{BDNF}$, indicating that ERK is not required in the P2X4R-BDNFsignaling pathway in microglia. In contrast, treatment with the p38-MAPK inhibitor, SB203580, not only prevented the P2X4Revoked increase in BDNF synthesis, but it also blocked the early phase of BDNF release. This finding implies that activation of p38-MAPK by ATP is necessary for the release of BDNF from the pre-existing pool, and together with the $\mathrm{Ca}^{2+}$ dependence of the early phase release, a mechanistically simple explanation is that $\mathrm{Ca}^{2+}$ induces activation of $\mathrm{p} 38$-MAPK, which in turn stimulates BDNF release. $\mathrm{Ca}^{2+}$-dependent activation of $\mathrm{p} 38$-MAPK has been demonstrated in a number of cell types (Blanquet, 2000; Dehez et al., 2001) including immune cells (Kreideweiss et al., 1999; Elzi et al., 2001; Shigemoto-Mogami et al., 2001). There is, however, no evidence in the literature for involvement of p38MAPK in the process of release of peptides from cells, and therefore, an alternative possibility is that activation of p38-MAPK is permissive for $\mathrm{Ca}^{2+}$-dependent BDNF release.

In conclusion, we have discovered that stimulation of $\mathrm{P} 2 \mathrm{X} 4 \mathrm{Rs}$ by ATP causes the SNARE-mediated release and synthesis of BDNF that is dependent on extracellular $\mathrm{Ca}^{2+}$ and activation of p38-MAPK. By demonstrating that p38-MAPK is a cellular intermediary in the release of BDNF evoked by stimulating microglial P2X4Rs, the present findings provide a unifying mechanism for observations that the ongoing expression of neuropathic pain behaviors requires both the activation of P2X4Rs (Tsuda et al., 2003; Coull et al., 2005; Ulmann et al., 2008) and p38-MAPK (Jin et al., 2003; Tsuda et al., 2004; Zhuang et al., 2007). The results, therefore, unify previous seemingly disparate findings and point to signaling of P2X4Rs and p38-MAPK in microglia as being critical for the involvement of BDNF in pain behaviors after peripheral nerve injury. Thus, targeting the P2X4R-p38-MAPKsignaling pathway in spinal microglia could prove useful in the development of novel therapeutic approaches for treating pain hypersensitivity caused by nerve injury. In addition, involvement of microglial P2X4Rs reported after injury to a peripheral nerve is increasingly being found in other models of CNS pathology such as inflammation (Guo et al., 2005; Zhang et al., 2008), CNS injury (Schwab et al., 2005; Zhang et al., 2006), and in glioblastoma brain tumors (Guo et al., 2004). Therefore, the implications of our findings may extend not only to pathological pain states but also to a diversity of CNS disorders.

\section{References}

Altar CA, DiStefano PS (1998) Neurotrophin trafficking by anterograde transport. Trends Neurosci 21:433-437.

Bader MF, Taupenot L, Ulrich G, Aunis D, Ciesielski-Treska J (1994) Bacterial endotoxin induces $[\mathrm{Ca} 2+]$ i transients and changes the organization of actin in microglia. Glia 11:336-344.

Balkowiec A, Katz DM (2002) Cellular mechanisms regulating activitydependent release of native brain-derived neurotrophic factor from hippocampal neurons. J Neurosci 22:10399-10407.

Blanquet PR (2000) Identification of two persistently activated neurotrophin-regulated pathways in rat hippocampus. Neuroscience 95:705-719.

Buldyrev I, Tanner NM, Hsieh HY, Dodd EG, Nguyen LT, Balkowiec A (2006) Calcitonin gene-related peptide enhances release of native brainderived neurotrophic factor from trigeminal ganglion neurons. J Neurochem 99:1338-1350.

Canossa M, Griesbeck O, Berninger B, Campana G, Kolbeck R, Thoenen H (1997) Neurotrophin release by neurotrophins: implications for activitydependent neuronal plasticity. Proc Natl Acad Sci U S A 94:13279-13286.

Castle JD, Guo Z, Liu L (2002) Function of the t-SNARE SNAP-23 and secretory carrier membrane proteins (SCAMPs) in exocytosis in mast cells. Mol Immunol 38:1337-1340.
Chang L, Karin M (2001) Mammalian MAP kinase signalling cascades. Nature 410:37-40.

Chen WG, Chang Q, Lin Y, Meissner A, West AE, Griffith EC, Jaenisch R, Greenberg ME (2003) Derepression of BDNF transcription involves calcium-dependent phosphorylation of MeCP2. Science 302:885-889.

Coull JA, Beggs S, Boudreau D, Boivin D, Tsuda M, Inoue K, Gravel C, Salter MW, De Koninck Y (2005) BDNF from microglia causes the shift in neuronal anion gradient underlying neuropathic pain. Nature 438:1017-1021.

D'Antoni S, Berretta A, Bonaccorso CM, Bruno V, Aronica E, Nicoletti F, Catania MV (2008) Metabotropic glutamate receptors in glial cells. Neurochem Res 33:2436-2443.

Dehez S, Daulhac L, Kowalski-Chauvel A, Fourmy D, Pradayrol L, Seva C (2001) Gastrin-induced DNA synthesis requires p38-MAPK activation via $\mathrm{PKC} / \mathrm{Ca}(2+)$ and Src-dependent mechanisms. FEBS Lett 496:25-30.

Elzi DJ, Bjornsen AJ, MacKenzie T, Wyman TH, Silliman CC (2001) Ionomycin causes activation of $\mathrm{p} 38$ and p42/44 mitogen-activated protein kinases in human neutrophils. Am J Physiol Cell Physiol 281:C350-C360.

Färber K, Kettenmann H (2006) Purinergic signaling and microglia. Pflugers Arch 452:615-621.

Gallagher CJ, Salter MW (2003) Differential properties of astrocyte calcium waves mediated by P2Y1 and P2Y2 receptors. J Neurosci 23:6728-6739.

Ghosh A, Carnahan J, Greenberg ME (1994) Requirement for BDNF in activity-dependent survival of cortical neurons. Science 263:1618-1623.

Guo LH, Trautmann K, Schluesener HJ (2004) Expression of P2X4 receptor in rat C6 glioma by tumor-associated macrophages and activated microglia. J Neuroimmunol 152:67-72.

Guo LH, Trautmann K, Schluesener HJ (2005) Expression of P2X4 receptor by lesional activated microglia during formalin-induced inflammatory pain. J Neuroimmunol 163:120-127.

Hepp R, Perraut M, Chasserot-Golaz S, Galli T, Aunis D, Langley K, Grant NJ (1999) Cultured glial cells express the SNAP-25 analogue SNAP-23. Glia 27:181-187.

Inoue K (2006) The function of microglia through purinergic receptors: neuropathic pain and cytokine release. Pharmacol Ther 109:210-226.

Ji RR, Woolf CJ (2001) Neuronal plasticity and signal transduction in nociceptive neurons: implications for the initiation and maintenance of pathological pain. Neurobiol Dis 8:1-10.

Jin SX, Zhuang ZY, Woolf CJ, Ji RR (2003) p38 mitogen-activated protein kinase is activated after a spinal nerve ligation in spinal cord microglia and dorsal root ganglion neurons and contributes to the generation of neuropathic pain. J Neurosci 23:4017-4022.

Keller AF, Beggs S, Salter MW, De Koninck Y (2007) Transformation of the output of spinal lamina I neurons after nerve injury and microglia stimulation underlying neuropathic pain. Mol Pain 3:27.

Khakh BS, Burnstock G, Kennedy C, King BF, North RA, Séguéla P, Voigt M, Humphrey PP (2001) International union of pharmacology. XXIV. Current status of the nomenclature and properties of P2X receptors and their subunits. Pharmacol Rev 53:107-118.

Kolarow R, Brigadski T, Lessmann V (2007) Postsynaptic secretion of BDNF and NT-3 from hippocampal neurons depends on calcium calmodulin kinase II signaling and proceeds via delayed fusion pore opening. J Neurosci 27:10350-10364.

Kreideweiss S, Ahlers C, Nordheim A, Rühlmann A (1999) Ca2+-induced p38/SAPK signalling inhibited by the immunosuppressant cyclosporin A in human peripheral blood mononuclear cells. Eur J Biochem 265:1075-1084.

Kuczewski N, Porcher C, Ferrand N, Fiorentino H, Pellegrino C, Kolarow R, Lessmann V, Medina I, Gaiarsa JL (2008) Backpropagating action potentials trigger dendritic release of BDNF during spontaneous network activity. J Neurosci 28:7013-7023.

Lauterborn JC, Rivera S, Stinis CT, Hayes VY, Isackson PJ, Gall CM (1996) Differential effects of protein synthesis inhibition on the activitydependent expression of BDNF transcripts: evidence for immediate-early gene responses from specific promoters. J Neurosci 16:7428-7436.

Lever IJ, Bradbury EJ, Cunningham JR, Adelson DW, Jones MG, McMahon SB, Marvizón JC, Malcangio M (2001) Brain-derived neurotrophic factor is released in the dorsal horn by distinctive patterns of afferent fiber stimulation. J Neurosci 21:4469-4477.

Lipsky RH, Xu K, Zhu D, Kelly C, Terhakopian A, Novelli A, Marini AM (2001) Nuclear factor kappaB is a critical determinant in N-methyl-Daspartate receptor-mediated neuroprotection. J Neurochem 78:254-264. 
Lowenstein CJ, Tsuda H (2006) N-ethylmaleimide-sensitive factor: a redox sensor in exocytosis. Biol Chem 387:1377-1383.

Mannion RJ, Costigan M, Decosterd I, Amaya F, Ma QP, Holstege JC, Ji RR, Acheson A, Lindsay RM, Wilkinson GA, Woolf CJ (1999) Neurotrophins: peripherally and centrally acting modulators of tactile stimulusinduced inflammatory pain hypersensitivity. Proc Natl Acad Sci U S A 96:9385-9390.

Marini AM, Jiang X, Wu X, Tian F, Zhu D, Okagaki P, Lipsky RH (2004) Role of brain-derived neurotrophic factor and NF-kappaB in neuronal plasticity and survival: from genes to phenotype. Restor Neurol Neurosci 22:121-130.

Matsushita K, Morrell CN, Lowenstein CJ (2005) A novel class of fusion polypeptides inhibits exocytosis. Mol Pharmacol 67:1137-1144.

Montana V, Malarkey EB, Verderio C, Matteoli M, Parpura V (2006) Vesicular transmitter release from astrocytes. Glia 54:700-715.

Morrell CN, Matsushita K, Lowenstein CJ (2005) A novel inhibitor of $\mathrm{N}$-ethylmaleimide-sensitive factor decreases leukocyte trafficking and peritonitis. J Pharmacol Exp Ther 314:155-161.

Nasu-Tada K, Koizumi S, Tsuda M, Kunifusa E, Inoue K (2006) Possible involvement of increase in spinal fibronectin following peripheral nerve injury in upregulation of microglial P2X4, a key molecule for mechanical allodynia. Glia 53:769-775.

North RA (2002) Molecular physiology of P2X receptors. Physiol Rev 82:1013-1067.

Obata K, Yamanaka H, Dai Y, Mizushima T, Fukuoka T, Tokunaga A, Noguchi K (2004) Differential activation of MAPK in injured and uninjured DRG neurons following chronic constriction injury of the sciatic nerve in rats. Eur J Neurosci 20:2881-2895.

Ralevic V, Burnstock G (1998) Receptors for purines and pyrimidines. Pharmacol Rev 50:413-492.

Rao JS, Ertley RN, Lee HJ, DeMar JC Jr, Arnold JT, Rapoport SI, Bazinet RP (2007) n-3 polyunsaturated fatty acid deprivation in rats decreases frontal cortex BDNF via a p38 MAPK-dependent mechanism. Mol Psychiatry 12:36-46.

Salter MW, Hicks JL (1995) ATP causes release of intracellular $\mathrm{Ca}^{2+}$ via the phospholipase $\mathrm{C}$ beta/IP3 pathway in astrocytes from the dorsal spinal cord. J Neurosci 15:2961-2971.

Scholz J, Woolf CJ (2007) The neuropathic pain triad: neurons, immune cells and glia. Nat Neurosci 10:1361-1368.

Schwab JM, Guo L, Schluesener HJ (2005) Spinal cord injury induces early and persistent lesional P2X4 receptor expression. J Neuroimmunol 163:185-189.

Shigemoto-Mogami Y, Koizumi S, Tsuda M, Ohsawa K, Kohsaka S, Inoue K (2001) Mechanisms underlying extracellular ATP-evoked interleukin-6 release in mouse microglial cell line, MG-5. J Neurochem 78:1339-1349.
Tao X, Finkbeiner S, Arnold DB, Shaywitz AJ, Greenberg ME (1998) Ca2+ influx regulates BDNF transcription by a CREB family transcription factor-dependent mechanism. Neuron 20:709-726.

Tsuda M, Shigemoto-Mogami Y, Koizumi S, Mizokoshi A, Kohsaka S, Salter MW, Inoue K (2003) P2X4 receptors induced in spinal microglia gate tactile allodynia after nerve injury. Nature 424:778-783.

Tsuda M, Mizokoshi A, Shigemoto-Mogami Y, Koizumi S, Inoue K (2004) Activation of p38 mitogen-activated protein kinase in spinal hyperactive microglia contributes to pain hypersensitivity following peripheral nerve injury. Glia 45:89-95.

Tsuda M, Inoue K, Salter MW (2005) Neuropathic pain and spinal microglia: a big problem from molecules in "small" glia. Trends Neurosci 28:101-107.

Tsuda M, Toyomitsu E, Komatsu T, Masuda T, Kunifusa E, Nasu-Tada K, Koizumi S, Yamamoto K, Ando J, Inoue K (2008) Fibronectin/integrin system is involved in $\mathrm{P} 2 \mathrm{X}(4)$ receptor upregulation in the spinal cord and neuropathic pain after nerve injury. Glia 56:579-585.

Ulmann L, Hatcher JP, Hughes JP, Chaumont S, Green PJ, Conquet F, Buell GN, Reeve AJ, Chessell IP, Rassendren F (2008) Up-regulation of P2X4 receptors in spinal microglia after peripheral nerve injury mediates BDNF release and neuropathic pain. J Neurosci 28:11263-11268.

West AE, Chen WG, Dalva MB, Dolmetsch RE, Kornhauser JM, Shaywitz AJ, Takasu MA, Tao X, Greenberg ME (2001) Calcium regulation of neuronal gene expression. Proc Natl Acad Sci U S A 98:11024-11031.

Yajima Y, Narita M, Usui A, Kaneko C, Miyatake M, Narita M, Yamaguchi T, Tamaki H, Wachi H, Seyama Y, Suzuki T (2005) Direct evidence for the involvement of brain-derived neurotrophic factor in the development of a neuropathic pain-like state in mice. J Neurochem 93:584-594.

Zhang Z, Artelt M, Burnet M, Trautmann K, Schluesener HJ (2006) Early infiltration of $\mathrm{CD} 8+$ macrophages/microglia to lesions of rat traumatic brain injury. Neuroscience 141:637-644.

Zhang Z, Zhang ZY, Fauser U, Schluesener HJ (2008) Mechanical allodynia and spinal up-regulation of $\mathrm{P} 2 \mathrm{X}(4)$ receptor in experimental autoimmune neuritis rats. Neuroscience 152:495-501.

Zhou Z, Hong EJ, Cohen S, Zhao WN, Ho HY, Schmidt L, Chen WG, Lin Y, Savner E, Griffith EC, Hu L, Steen JA, Weitz CJ, Greenberg ME (2006) Brain-specific phosphorylation of $\mathrm{MeCP} 2$ regulates activity-dependent Bdnf transcription, dendritic growth, and spine maturation. Neuron 52:255-269.

Zhuang ZY, Kawasaki Y, Tan PH, Wen YR, Huang J, Ji RR (2007) Role of the CX3CR1/p38 MAPK pathway in spinal microglia for the development of neuropathic pain following nerve injury-induced cleavage of fractalkine. Brain Behav Immun 21:642-651. 